\title{
COMMUNITY PARTICIPATION IN SOLID WASTE MANAGEMENT: THE CASE OF KURUNAGALA MUNICIPAL COUNCIL IN THE NORTH WESTERN PROVINCE OF SRI LANKA
}

\author{
Mallika Pinnawala \\ Department of Sociology, University of Peradeniya , Peradeniya , Sri Lanka \\ Acknowledge: 7 Apr 2016 Revise: 13 June $2016 \quad$ Accepted: 29 July 2016
}

\begin{abstract}
Solid Waste Management (SWM) refers to the supervising and handling of SW from its generation to disposal. As a developing country, in Sri Lanka, Solid Waste has become one of the growing national problems, especially in urban areas where there is no proper mechanism to manage it. Citizens always assume that SWM is a responsibility of Local Authorities (LAs). But waste is generated from human activities and citizens also have a responsibility in managing them. Therefore community participation is a crucial factor for sustainable SWM process in a country. There are two objectives of this study, namely, to examine community strategies in managing SW at the household level and to understand community cooperation with LAs in managing it in community level. The study was conducted in one administrative zone in Kurunagala Municipal Council in the North Western Province of Sri Lanka covering 160 households selected through simple random sampling method. A Questionnaire survey was used to collect data to understand community participation in SWM at the household level. In-depth interviews with Municipal Council (MC) officers and sanitary labours who are involved in SWM of the Municipal Council were conducted to gather data on community cooperation with LA in Managing SW. The study revealed around $90 \%$ of residents use one strategy of $3 \mathrm{R}$ concept in managing SW. Reduced solid waste through reuse is a popular and common strategy used by the respondents in the area. The percentage is around $88 \%$. Respondents also prefer recycling and separation to manage their household solid waste but the facilities provided by the LA are not sufficient. Some people are not aware of the problem of solid waste and also about managing strategies of solid waste. According to LA officers, community cooperation for solid waste management is at average level.
\end{abstract}

Keywords : Sri Lanka ,Solid Waste Management, Community Participation, Local Authorities Municipal Council, 3R concept,

\section{INTRODUCTION}

Generally human activities generate waste materials that are often discarded as useless. (Tchobanoglous \& Kreith, 2002). According to the United State's Environmental Protection Act of 1990, "waste is defined as any substance which constitutes a scrap material or an effluent or unwanted surplus substance which required to be disposed" (Daniel \& Ibok, 2013 cited by Madu, 2004: 47). They are normally solid in the appearance and are generated from human or animal activities (Hettiarachchi, 2006: Werellagama \& Abeynayaka, 2006). The quantity of Solid Waste generation increases day by day creating problems that require a system for waste management. However Solid Waste Management is a complex process because it involves many technologies and disciplines. These include technologies associated with the control of generation, handling, storage, collection, transfer, transportation, processing and disposal of solid waste. (Tchobanolous \& Kreith, 2002:3). Therefore Solid Waste Management (SWM) refers to the supervising handling of Solid Waste (SW) from its generation to disposal.

Rapid increase of Solid Waste due to urbanization , industrialization, economic growth and development of infrastructure facilities is becoming a burgeoning problem all over the world. Especially in developing countries solid waste can be seen as a multidimensional threat and challenge to the physical as well as social environment. SWM becomes a foremost challenge and issue in urban areas, particularly in the rapidly urbanizing areas of developing countries (Shukor et al, 2011; Alwis, 2006). A World Bank report estimates SW in urban areas of East Asia alone will increase from 760,000 to 1.8 million tons per day within 25 years. 
Parallel to that waste management costs will double from US\$ 25 billion to US\$ 47 billion by 2025 (Ahmed \& Ali, 2004 cited in Urban age, 1999). Further, Municipal Solid Waste (MSW) is a pressing problem that has become more severe over the last ten years (Karunasena \& Wickramasundara, 2012). The global urban MSW production, which has nearly doubled in the last 10 years, is projected to double again in the next 15 years, increasing from 1.3 billion tons a year in 2010 to 2.2 billion tons a year in 2025 (Courtois, n.d).

In Sri Lanka, Solid Waste has become one of the growing national problems and both the national government and Local Authorities are facing the problem of managing solid waste effectively and sustainably. Community members always assume that SWW is a responsibility primarily of Local Authorities (LAs) but as waste is generated from human activities the general public also have a responsibility in managing it. Therefore community participation is a crucial factor for the sustainable SWM process. The community can participate in SWM activities in two ways . First, they can manage those waste at their household level using their own strategies such as using of compost pits, reusing etc . Second, they can adhere to instructions given by LAs and cooperate to the programme or activities conducted by them. In broader sense both can be considered as community participation. Based on this assumption there are two objectives of the study, namely, to examine community strategies in managing SW at household level and to understand community cooperation with LAs in managing SW. The study was conducted in one administrative zone in Kurunagala Municipal Council in the North Western Province of Sri Lanka.

\section{Solid Waste Management in Sri Lanka : An Overview}

Sri Lanka is one of the developing countries that is exposed to environment issues, now becoming a threat to the wellbeing of the people. This situation can be attributed primarily to industrial expansion that began with the introduction of the Open Economy in 1977 that resulted in many changes in Sri Lanka in terms of economics, social and cultural development. Expansion of mechanization, rapid industrialization, development of infrastructure facilities, movement of people into urban centers -urbanization, and also changes in the consumption patterns are some of these. With these developments solid waste generation increased and has today become one of the pressing national problems that is causing many environmental and health problems in the country (Pilapitiya 2006). The reason is that there is no proper mechanism to manage the solid waste in proportion to the generation ( Bandara and Hettiarachi 2010). The problem is more critical in urban areas where experiencing problem of having not enough space to cater to the needs of the rapidly increasing population.

Therefore problem of solid waste needs to be treated as an urgent and priority item in the development agenda of Sri Lanka. Under the provisions of the Local Government Act, the Local Authorities (LAs) in Sri Lanka are responsible for collection and disposal of waste generated by inhabitants within their respective administrative area. The National Environmental Act provides the necessary legal and logistic framework for environmental protections in the country and the Central Environment Authority (CEA) is the government established agency within the Ministry of Environment and Natural Resources formulating guidelines and doing regulating work. Overall, the National Solid Waste Management Support Center 
(NSWMSC) gives the technical assistance necessary to LAs in the field of solid Waste Management. But in most of the local authorities the Department of Health is playing an active role in waste management. However, very few local authorities have a separate unit for waste management. Irregular waste disposal methods are polluting ground water, air and soil. Leachate coming from these waste dumps is easily added to surface water bodies as well as ground water. Heavy metals such as Cadmium can be added to the wells around those dump sites creating serious health problems that in turn leading to social problems

In Sri Lanka the total Municipal Solid Waste (MSW) generation is around 6400 tons per day and the per capita per day waste generation on average is $0.25-0.5 \mathrm{Kg}$ ( Wijethunga 2012 ). The total collection in urban areas is about 10,497 tons per day in Sri Lanka (NSWMSC 2014) ) and this amount typically consists of very high percentage of perishable organic waste that includes food and garden waste (SATREPS 2014). However waste collection in the Western Province where the capital of the country situated is about 1660 tons per day which is about $60 \%$ of the total waste collection of the country. The next highest waste collecting province is the Central Province where the second biggest city is situated. This situation clearly shows the relationship between the amount of waste collection and urbanization or population density in Sri Lanka . According to the available data, solid waste composition in Sri Lanka consists of $62 \%$ biodegradable waste, $6.5 \%$ of paper, $6 \%$ polythene and plastic, $6 \%$ of wooden $2 \%$ glass. It reveals that the Sri Lankan municipal solid waste consists of a large proportion of compostable materials (Liyange 2016 ). Of the waste collected residential waste accounted for $55 \%$ - $65 \%$ out of the total MSW generation (Bandara 2008). Further, the collection of solid waste in the country is very poor and there are areas without any waste collection even within some municipality boundaries. Generally solid waste is not collected by LAs from rural areas in Sri Lanka.

In Sri Lanka, until recently solid waste management was primarily by means of collection, transport and dumping, which is generally done in open spaces. Since degraded land was freely available waste dumping was not a big problem for local authorities in the past. The final disposal of waste into open dumps in the country is more than $95 \%$ and today many LAs in Sri Lanka regularly dispose waste in open bare lands or in environmentally sensitive areas like river banks, marshy lands for convenience \& for financial reasons. However there have been many public protests and even court cases against local authorities that engage in this practice. The problem is further confounded today by land scarcity which is now a major problem faced by local authorities who used to dump their waste on bare land in the past. According to the World Bank Report (1999) the estimated solid waste generation per person is $1 \mathrm{~kg}$ in 2025 in Sri Lanka. Considering these problems the government and other agencies in Sri Lanka have begun to pay their attention to 'controlled sanitary landfills' through proper solid waste management mechanism. This mechanism includes technologies associated with the control of generation, handling storage, collection, transfer transportation, processing and disposal of solid waste ( Techobanolous \& Kreith 2002). In a nutshell, SWM is a systematic process that manage SW from generation to final disposal involving many disciplines from Physical science to social science. A sustainable SWM system should be economically viable, socially acceptable and environmentally effective (Wijetunga, 2012). For that the problem should be approached with close participation of LAs, working with local communities (Pilapitiya, 2006). This makes community participation a crucial factor for the sustainable SWM process (Bernstein, 2004). Therefore 
participation of the community in sustainable solid waste management is timely important factor for the country.

\section{METHODOLOGY}

The study was conducted in one out of 12 administrative zones, namely "Lake Zone" in Kurunagala Municipal Council in the North Western Province of Sri Lanka. There are three main reasons to select this area for the study . First, it is the $3^{\text {rd }}$ largest zone of the area and closer to the main city. Second, this area represent all three main ethnic groups of Solid Waste is remaining. According to officers of the LA one of the main reasons is less cooperation of community. of the country so that cultural diversity is well represented in the study area .Third,this are is the only place that balance the business places as well as residential neighborhoods of the community .

The main economic activities in this area is paddy and coconut cultivation. Tourism also is important in this area due to the historical importance of the area . Majority of the population is Sinhalese followed by Muslims There are several strategies and programs that have operating in the area under the Municipal Council of Kurunagala. Still the problem
Map 1

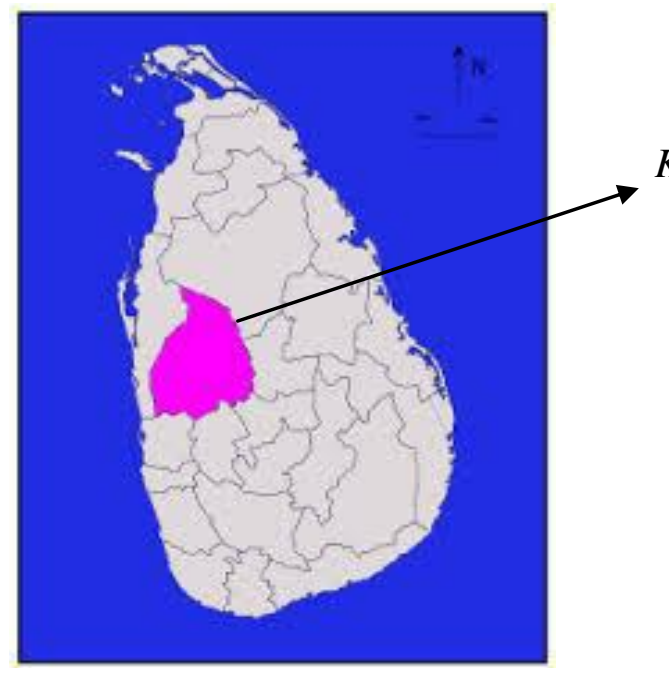

Source: www.googlemap.com,2014

Out of 374 households of the zone 160 were selected for the study randomly representing all the cultural social and also economic diversities of the area The study unit was individual household. Survey was
Map 2

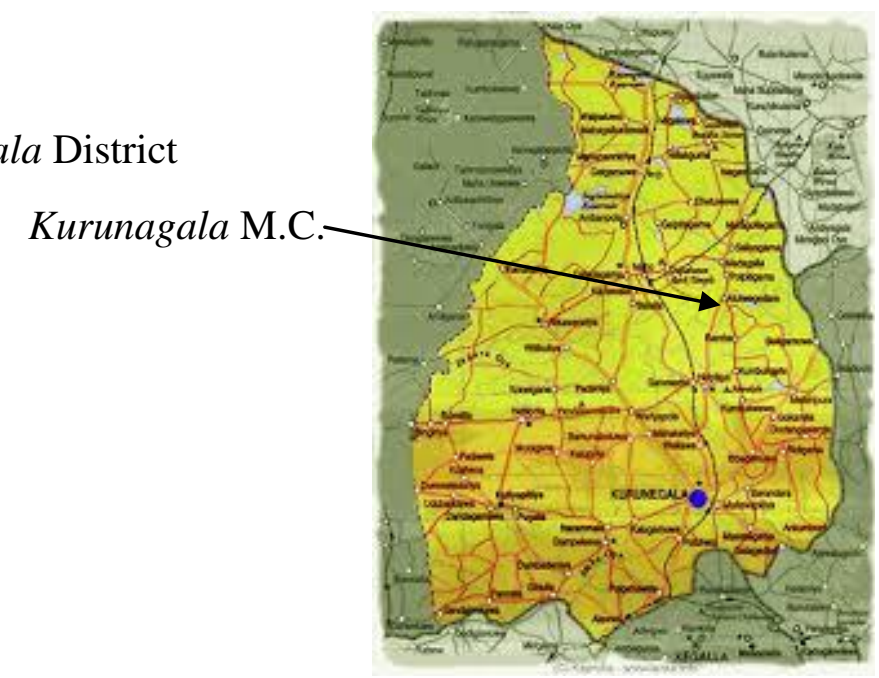

conducted when all the household members were at home. The data collection from the household involved discussions with members irrespectively their gender and age . But it was noted that more women were actively 
participating in discussions providing detail information compared to the males of the households. Primary data was collected using self-administrated questionnaire survey and in-depth interview method. Questionnaire survey was used to collect data from residents of each MC covering the solid waste practices and also such other issues as their participation in the SWM process, awareness, problems and relationship with LA related to SWM. The in-depth interviews were carried out with responsible officers' related to SWM in each MC such as Public Health Inspector, Head of the solid waste management unit of the Municipal Council, Environment officers and the Environmental police representative to collect institutional data on SWM. In addition in-depth interviews were also conducted with four sanitary labours, who collect garbage from households to understand the behavior of citizens they deal with.

\section{RESULTS AND DISCUSSION}

\section{Community Participation in Solid Waste Management}

Basically Solid waste is generated through human activities therefore it is important to understand whether people realize the management of solid waste is also the responsibility of them. In this regard the knowledge of respondents on SWM process is significant. The survey reveals that $30 \%$ of the respondents have sufficient knowledge on SWM. They understand SW is a problem created by human so that managing is the responsibility of them. Further they always try to support and cooperate the MC's efforts in managing solid waste Meanwhile $65 \%$ of respondents have a fair knowledge and they know that there are many problems due to the SW . But they are not worried about these problems since they think managing is a responsibility of the Municipal council. It is interesting to note that $5 \%$ of respondent do not have any knowledge about the necessity of manage the solid waste. Following figure (figure1) shows this information.

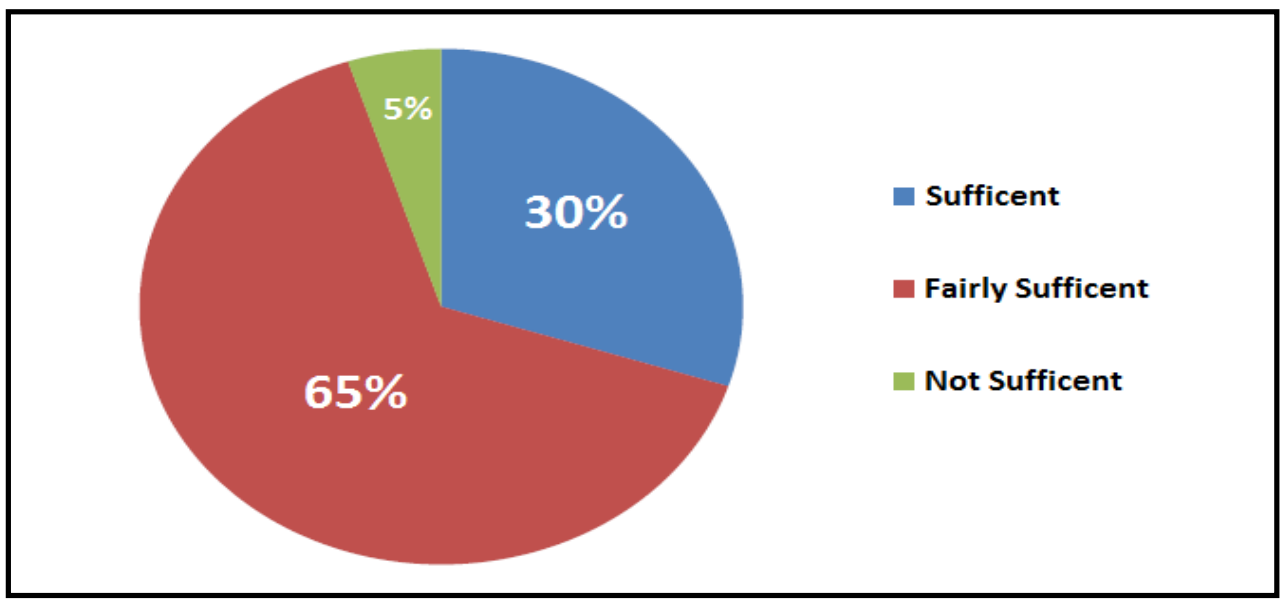

Figure 1: Knowledge of SWM

Source: Field survey 2014
In addition, the survey contrast to some early studies found that there is no direct and positive relationship between education level and concern for environment 
and education and income. For an example Shen and Saijo (2008) found the people with higher income and who are better educated engage in better environmental practices compared to lower income and less educated people. But in this study it is interesting to note there is no significant different between education level and the knowledge of SWM even for SWM activities Some respondents were found participating in SWM activities without knowing the seriousness of the problem of SW. Further $90 \%$ of the respondent are not satisfied with awareness program conduct by the Municipal Council .

\section{Community strategies in managing $S W$ at the Household level:}

As pointed out earlier in Sri Lanka waste disposal is a crucial problem for the local authority due to the high amount of the waste they have to handle and lack of suitable places to dispose it . One possible solution to the problem is reduction of waste generated and this can be achieved using through several strategies. Data from households that were studied showed that $42.5 \%$ of the households were actively involved in reducing their solid waste using several strategies

According to the respondents who are not involving in reducing the waste, they do not have time to use strategies to reduced waste generated at the household level due to their busy schedule $t$ and lack of facilities. Several members of households also mentioned that they do not have proper knowledge in strategies to reduce household solid waste.

Reuse: This is one of the strategies that can be used to reduce waste generation. The Kurunagala Municipal council has conducted several awareness programmes regarding reuse not only for households but also for school children in the area. In the study it was found that $90 \%$ of the households practice reusing of materials. Especially housewives of the study are very keen to reuse even though many of them do not know how much it helps to reduce the waste. This tendency among women to reuse waste may be attributed to the fact that women are generally more careful in the use of what is available i.e., thrifty compared to men. It is important to educate them further as this quality is considered innate to women and therefore can be better used in solid waste management. Moreover there is a public market sponsored by Kurunagala Municipal council where households can sell reusable material available in households. Unfortunately the study found that $90 \%$ of the respondent were not aware of this market.

Waste Separation : The Kurunagala MC always expects community participation for sustainable solid waste management within their territory. As one step in this direction the $\mathrm{MC}$ requests its residents to separate the waste and if not refuse reusable material .The study shows that $72.5 \%$ of respondents accepted that they should separate the waste . According to them the main reason for this acceptance is to make easy the role of SWM activities of MC. In addition the rule imposed by $\mathrm{MC}$ is also another important factor to separate the waste since most of the households have faced the experience of garbage collectors refusing to accept the waste that is not separated. Though $72.5 \%$ of respondent accepted that waste should be separate only $45 \%$ of them practice waste separation at their household.

Further, the data also reveals that there was no relationship between awareness of solid waste management as a solution to the problem solid waste and the practice of separation of solid waste. It was revealed from the study that many respondents who were aware of problems created by solid waste and had knowledge of solid waste management did not separate their household waste. Following table ( Table 1) shows this situation. 
Table 1: Knowledge of SWM and Waste separation

\begin{tabular}{|c|c|c|}
\hline Level of knowledge & \multicolumn{2}{|c|}{ Waste separation } \\
\hline & Separate & Not separate \\
\hline Sufficient & 58.4 & 41.6 \\
\hline Fair & 38.5 & 61.5 \\
\hline No & 50.0 & 50.0 \\
\hline
\end{tabular}

Source: Field Survey 2014

It was also found that many households did not use even facilities provided to them for separation of waste. According to the information provided by Municipal council officers households in the study area have been provided with polythene bags for waste separation. But only $64 \%$ of the household were using these bags for the purpose the bags have been given. This was admitted by the householders too. The following are typical responses of householders who gave reasons for them not using the bags provided by the Municipal Council for waste separation. A respondents said,

"Nearly a year ago MC gave us black bags but those are not strong enough to hold waste. they leak and therefore are not suitable for storing kitchen waste so we cannot use them"

Another householder claimed "We used the bags given to us by the MC for very short period with difficulty but we found they were not suitable. We bought baskets ourselves but that cost money so we do not separate waste now".

Further the researcher found that even the households that separate waste use their own baskets not only for the fact that the bags provided by the Council are not suitable but also because $\mathrm{MC}$ has not been regular in providing them. In fact the Council no longer provides bags to households. . Therefore it is difficult to see how community cooperation can be achieved in getting the householders to separate waste when the Municipal Council has failed in its responsibilities. .

Composting at the household level: Through this method people can help the Local Authorities to reduce the amount of the waste available for collection and disposal. As mentioned earlier disposal is the major problem Sri Lanka is facing in SWM. The Kurunagala MC is producing compost using degradable waste but in the study area many people are not producing compost though the MC distributes composting equipment, i.e., barrels, among households. Statistically it is reported that only $20 \%$ of respondent are involved in compost production at their home in the study area. Lack of space is one of the problems these households are faced with even if they want to compost their waste. It was found that those households with relatively bigger home gardens are often the ones that have adopted composting as part of waste management at home

Recycling: Recycling is an efficient and cost effective method of waste management as it is one of the better ways to reduce the bulk waste that goes to the disposal site. At present the Sri Lankan government pays special attention to recycling of solid waste materials. In the study area, the MC collects only polythene and plastic materials for recycling . The other recyclable materials that residents 
have can handover to the place called "Sampath Piyasa" (Resource Centre). The study revealed that people who belong to lower income categories are the main customers of this center not the affluent households. These low income householders bring not only their recyclable material but also the recyclable items from rich households that they collect free of charge and sell those to the center. Members of high income household because they have the attitudes that 'selling waste damages their social status" they prefer to give their recyclable items free of charge to poor people or sell them at home at a lower price without going to the Centre. On the one hand this explains why poor householders are the majority customers of the Centre and on the other also provides a solution to problem.

\section{Community cooperation with LAs in managing $S W$ at the Community level}

A successful solid waste management strategy requires community cooperation for which it is necessary for the LA to maintain a good dialogue with the community as the relationship between community and the municipal council is very important to achieve results. The community must know what the Council is doing and the benefits it receives for the services of the Council. In addition the trust between the Municipal Council and the community and the willingness of the latter to cooperate with the programmes conducted by $\mathrm{MC}$ are some vital factors. The following figure ( figure 2) clearly shows that though the majority of the people $(67 \%)$ agreed with the MC in its solid waste management work while there is a significant proportion i.e., $33 \%$ of the people who do not agree with the work MC is doing in solid waste management.

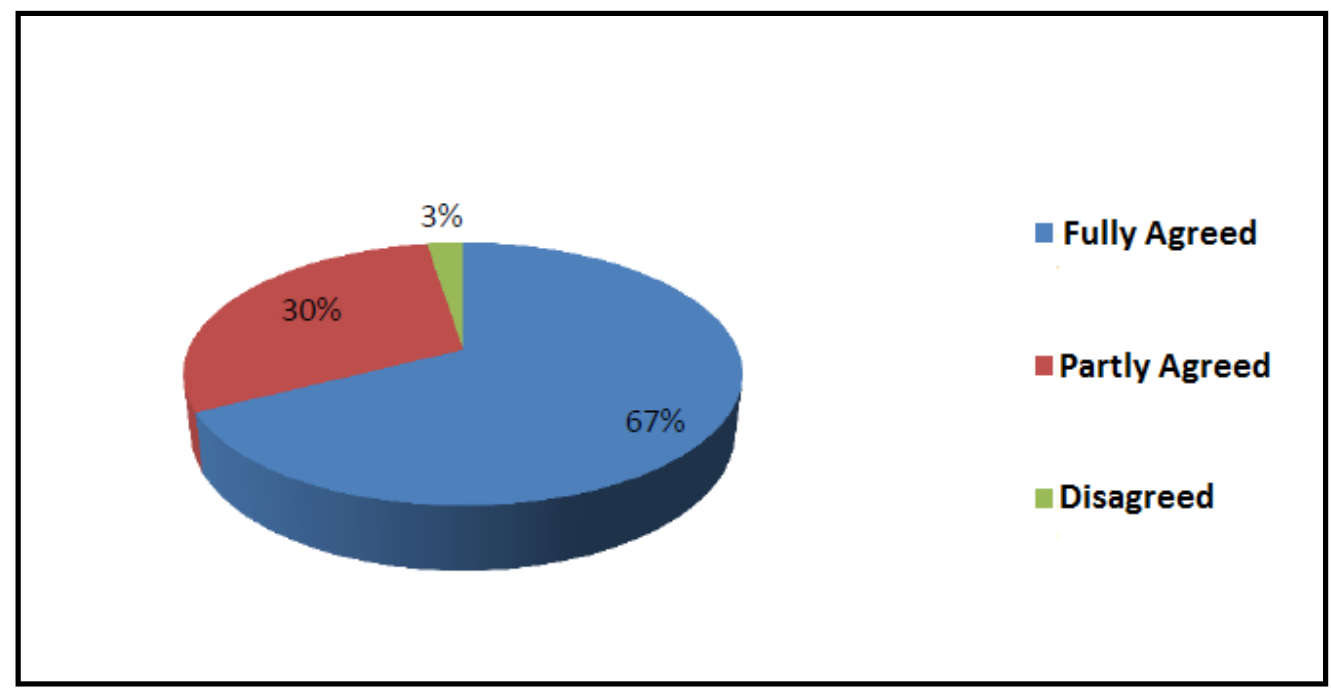

Figure 2: Agreement on Programs

\begin{abstract}
Further, the study found that there many Community Based Organizations(CBOs) are operating in the area based on the community necessities . Basically through CBOs it is very easy to take
\end{abstract}

community participation for activates operating in their own territory effectively as well as efficiently. But in the study area . it was revealed that majority of people like to work at least with one the Community 
Based Organization(CBOs ) but $15 \%$ of the respondents are not members of any organizations. Though CBOs are very important to mobilize support for SWM process at the community there is no any single CBOs in the area conducting any programme related to SWM. It is one of the reasons for the increase of the SWM problem day by day in the area.

\section{CONCLUSION}

In the study area the community can take part in solid waste management activities either at household level or cooperate with municipal Council activities and programmes. But according to the information received from the survey people are not concerned about the problem. Though many of them know that SW adversely affects the environment hence create other problems such as health, social etc. people always thought it is a responsibility of the Municipal Council. Due to this the SW problem is still remaining in the area.

Further, the study reveals that while there is awareness of problems of solid waste and moderate levels of support from the community the solid waste management work in the area has more to achieve and lot of work needs to be done to make the work of the MC a success. There is still a considerable number of people who are not aware of the seriousness of the problem of solid waste . This situation has not changed even with the education level of the community and efforts by the MC to create awareness. This situation adversely affect participation of the community in SWM activities in the study area. Another problem that negatively affects solid waste management efforts in the area is the lack of alternatives, i.e., lack of community based organizations to mobilize people. .
However in the study area around $90 \%$ of residents at least use one strategy of $3 R$ concept in managing SW. Reduced solid waste through reuse is a popular and also is the common strategy used by the respondents in the area. It is interesting to note some are doing this as a habit without not knowing the positive benefits. The percentage is around $88 \%$. Respondents also prefer recycling and separation to manage their household solid waste but the facilities provided by the Local Authority are not sufficient

\section{REFERENCES}

Ali, M. \& Ahmed, S.A. (2004). Partnership for solid waste management in developing countries: linking theories to realities. Southern Rural Sociology. 28 (3), 467479.

http://www.sciencedirect.com/science/article/ pii/S0197397503000444 (accessed, 05 June , 2015)

Alwis, A.de(2006). Environmental impact of incineration as a means of solid waste disposal. Solid waste management in Sri Lanka:Opportunities and Constrains. University of Peradeniya, $25^{\text {th }}$ March 2006. University of Peradeniya: Faculty of Engineering. 21-23

Bandara ,N.J.G. J and Hettiarachhi J.P.A(2010)Environment Impacts with Waste Disposal Practices in a suburban Municipality in Sri Lanka, International Journal of Environment and Waste Management, Vol.6

Bandara, N. (2008). Municipal Solid Waste Management-The Sri Lankan Case. International Forestry and Environmental Symposium.

http://www.sci.sjp.ac.lk/ojs/index.php/fesy mpo/article/view/21/17 (accessed, 15 May, 2015) 
Bernstein Toolkit,. (2004).: Social Assessment and public participation in municipal solid waste management. Urban Environment Thematic Group.

Courtois, A.Le. (n.d). Municipal solid waste: turning a problem into resource http://www.proparco.fr/jahia/webdav/site/ proparco/shared/PORTAILS/Secteur_priv e_developpement/PDF/SPD15/SPD15_Al exandra_le_courtois_uk.pdf (accessed, 15 May, 2015

Hettiarchchi, K. (2006). Solid waste management in Sri Lanka. Solid waste management in Sri Lanka: Opportunities and Constrains. University of Peradeniya, $25^{\text {th }}$ March 2006. University of Peradeniya: Faculty of Engineering. 1-5

Karunasena, G. \& Wickramasundara, C. (2012). A comparison of municipal solid waste management in selected local authorities in Sri Lanka. Proceedings of International Conference of Sustainable Built Environment

\section{.http://www.civil.mrt.ac.lk/conference/ICSB} E2012/SBE-12-62.pdf (accessed, 13 May, 2015)

Pilapitiya, S. (2006).Challenges of solid waste management in Sri Lanka past, present and future. Solid waste management in Sri Lanka: Opportunities and Constrains. University of Peradeniya, $25^{\text {th }}$ March 2006. University of Peradeniya: Faculty of Engineering. 7-14

Shen J, T Saijo (2008) Reexamining the relations between socio-demographic characteristics and individual environmental concern: Evidence from Shanghai data, Journal of Environmental Psychology

Shukor, F.S.A., Mohammed, A.H., Sani, S.I.A \&Awang, M. (2011). A Review of the success factors for community participation in solid waste management. International conference on Management.

http://www.internationalconference.com.my/ proceeding/icm2011_proceeding/070_260 ICM2011_PG0962_0976_COMMUNIT Y_PARTICIPATION.pdf (accessed, 01 November, 2014)

Tchobanolous, G., \& Kreith, F., (2002). Handbook of Solid Waste Management. $2^{\text {nd }}$ ed. McGraw Hill: New York

Visvanathan ,C., (2006)Domestic Solid Waste Management in South Asia , 3R South Asia Expert Workshop, Katmandu , Nepal

Wijetunga, S. (2012). Community Views and Attitudes for Waste Management Improvement in a Higher Education Institute: Case Study. Journal of Environmental Professionals Sri Lanka. Vol.1 $\quad(1 \quad 57-69$ http://dx.doi.org/10.4038/jepsl.v1i1.5142 (accessed, 01 November, 2014)

World Bank (2012)What is Waste: A globalNetwork on Solid Waste Management Urban development Series Knowledge Paper ( $h$ ttps://openknowledge.worldbank.org/68 1350WP0REVIS0at0a0Waste) retrieved on $10 / 10 / 2014$ 